\title{
The Counter-Cultural Art of Dealing with Dirt: The Balmain Group's Sexual Revolution in Print
}

Jean-François Vernay

\section{OpenEdition}

1 Journals

Electronic version

URL: https://journals.openedition.org/ces/7534

DOI: 10.4000/ces.7534

ISSN: 2534-6695

Publisher

SEPC (Société d'études des pays du Commonwealth)

\section{Electronic reference}

Jean-François Vernay, "The Counter-Cultural Art of Dealing with Dirt: The Balmain Group's Sexual Revolution in Print", Commonwealth Essays and Studies [Online], 43.2 | 2021, Online since 23 July 2021 connection on 04 February 2022. URL: http://journals.openedition.org/ces/7534 ; DOI: https://doi.org/ $10.4000 /$ ces.7534

This text was automatically generated on 4 February 2022.

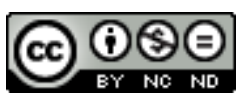

Commonwealth Essays and Studies is licensed under a Licence Creative Commons Attribution - Pas d'Utilisation Commerciale - Pas de Modification 4.0 International. 


\title{
The Counter-Cultural Art of Dealing with Dirt: The Balmain Group's Sexual Revolution in Print
}

\author{
Jean-François Vernay
}

If Martians had arrived in Australia before 1972
and read our literature, they would not have had
any clue about how human beings reproduced.
No wonder our population was going down.
Frank Moorhouse

1 Seeking to challenge the conservative and heteronormative views prevalent in Australian society right up until the 1970s, a group of writers, most of whom were geographically attached to Balmain, decided to give an empirical touch to the philosophical teachings of John Anderson in the 1950s and to the 1960s antiauthoritarian movement, both of which essentially stressed freedom of choice, questioned conventional morality and exposed the way society was setting restrictions on individual liberties. The loosening of censorship combined with the emancipatory social movements of the early 1970s had crystallised around the inclusion of representations of sexualities into narratives bent on showing alternative domestic lifestyles.

2 By restricting my scope to material published in the early 1970s, I will focus on two prolific Balmain Group fiction writers, namely Frank Moorhouse (born in 1938) and Michael Wilding (born in 1942) who were far more active in the Sydney Push than, say, Vicky Viidikas or Christine Townend. I shall start by establishing the historical and sociocultural context of the Balmain Group of writers, before discussing first the poetics and then the politics of sexuality in The Americans, Baby: A Discontinuous Narrative of Stories and Fragments and Living Together, respectively published in 1972 and 1974. 


\section{The Balmain Group of Writers: Exploring the Socio- Political Context}

3 In the introduction of his prolem sine matre creeatam book-length study of sexualities in Australian fiction, Messengers of Eros: Representations of Sex in Australian Writing (2009), Xavier Pons observes that "In the late 1960s and early 70s sex was officially pronounced to be enjoyable" until "[t]he appearance of AIDS put paid to the joys of promiscuity" $(2009,1){ }^{1}{ }^{1}$ In the wake of the American Sexual Revolution and its associated counterculture which gained momentum a decade earlier, the dissolution of the liberticidal censorship laws in the 1970s allowed Australian fiction writers to be more daring in their depictions or discussions of sexualities, at a time when the publishing industry worldwide was jumping on the bandwagon of sexual liberation politics by releasing sex manuals of all kinds (Ward 2015). Such context made it possible for a wind of libertine and libertarian changes to sweep over the Australian literary panorama and open up new perspectives: while erotic literature eventually developed and expanded, some more mainstream writers associated with realism included explicit graphic scenes and discussions of sexual relationships in their novels.

4 I see the Balmain Group of writers as being the literary spin-off of the Sydney Push. This Sydney-based left-leaning countercultural group of Libertarians with whom the Balmain Group has often been loosely associated gets a passing mention in "Five Incidents Concerning the Flesh and the Blood" (Moorhouse 1972, 80). With Frank Moorhouse and Michael Wilding as overlapping figures, the Sydney Push was mostly composed of writers, journalists, artists and researchers - such as Clive James, Robert Hughes, Germaine Greer, Robyn Davidson, Paddy McGuinness, Jim Baker, Darcy Waters, Lex Banning, Eva Cox, David Perry, Richard Appleton, David Makinson, Sasha Soldatow, to name a few. These Libertarians were for the most part under the intellectual influence of Scottish philosopher John Anderson (1893-1962) who taught at Sydney University and was renowned for his "criticisms of conventional morality and his account of positive ethical goods promoting a stance of commitment, endeavour, risk and critical opposition to merely customary expectations [...]" (Creagh 2018). Elizabeth Farrelly highlights the inherent bundle of contradictions within

the Push as a movement that was strongly moral yet anti-moralism; clearly hierarchical but anti-elitism; intensely political but disinclined to agitate for change; intensely verbal but leaving little written evidence; avowedly egalitarian but inclined to treat women as sexual conveniences; overwhelmingly heterosexual but with a hidden homoerotic competitiveness between the main men. (2009)

Often caricatured as a sex-driven socialising group, the Sydney Push was an antiauthoritarian movement embraced by a majority of young people in the late 1940s in order to fight "moralism, elitism, sexism, violence, religion, careerism, censorship and the hypocrisy of their use by a paternalistic state" (Farrelly 2009). While the spirit of the Sydney Push is said to have dissolved in the early 1970s after starting to peter out in the mid 1960s, it would appear that it survived in the informal gatherings of the Balmain group of writers. These intellectuals were perpetuating the postwar countercultural revolution by sublimating the political activism which underpinned the Sydney Push's heated discussions into creativity, thanks to their storytelling skills and publishing ventures. Michael Wilding gave an account of this alternative subculture lifestyle in his debut novel Living Together modelled on his experience of 
living in Paddington from 1964 to 1966 when the Sydney suburb was undergoing a process of gentrification. ${ }^{2}$

6 This inner-city house renovation project - satirically set against a bohemian backdrop paves the way for three key characters (Martin, his partner Ann, and his friend Paul) to experience the sexual joys of a community-living lifestyle which goes beyond mere house-sharing and its pooling of resources. Wilding perceived the Sydney Push as a premature post-Marxist movement and later confessed that some of those values, which he saw as "cynical libertarian bohemianism," "probably crept into some of the characters in Living Together" (qtd. in Syson 1998, 280).

7 It might be argued that the seeds for the sexual revolution in print were sown in the 1960 s by a knot of writers who would use the politics of sex as the backbone of their oeuvre. As Robert Dessaix has it,

the 1960s saw a small but powerful explosion of works dealing directly with questions of sexual orientation. In fact, sexuality itself has now become a leading theme in Australian fiction, poetry and drama, to the point where some writers have made literary careers writing about nothing else. $(1993,3)$

May I hastily add that this is certainly not the case of Frank Moorhouse or Michael Wilding, whose literary output has transcended the vested interest in sex one finds in their earlier works published in the 1970s. What is more, the question of sexual orientation - while apposite in Frank Moorhouse's short fiction portraying homosexual and bisexual intercourse - is irrelevant to Michael Wilding's novels which ultimately took a more political complexion from the publication of The Paraguayan Experiment (1984) onwards.

8 At the end of the 1960s, Frank Moorhouse and Michael Wilding along with a few other writers - namely Robert Adamson, Murray Bail, Rudi Krausmann, Robyn Ravlich, Nigel Roberts, Christine Townend, John Tranter and Vicky Viidikas - loosely constituted the "Balmain group," the name of which came from what was at the time the grungy leavings of a working-class industrial hub, west of central Sydney. Others like Michael Dransfield, Laurie Duggan and John Forbes occasionally joined the above-mentioned core group. What is known as the Balmain Group of Writers is a loose aggregate of emerging Australian writers who occasionally saw one another at bohemian parties but never congregated specifically for discussions on creative writing. For instance, Christine Townend did not know Murray Bail and Vicky Viidikas, but she spent time with Michael Wildling and Pat Woolley. The latter released her second novel Travels with Myself (1976) shortly after founding the Wild and Woolley publishing company. ${ }^{3}$ Although the Balmain Group of Writers had drafted no manifesto to put sexual aesthetics and politics on the literary agenda, it seems that a certain freedom of expression in relation to the literary treatment of sex characterises the fictitious stories from that era. While the group did not have any clear official aim, Nataša Kampmark argues that

they were brought together [...] by their shared dissatisfaction with the prevailing modes of writing and publishing in Australia. In order to break the confines of formal realism, they developed forms of surrealism and explored the possibilities of fantasy; they interrogated some of the most entrenched mythologies and eroded the values of old religious, social and writing forms. Their writing is also sometimes referred to as the new wave of writing. (Kampmark 2014, 3, n9)

The whole sociocultural context of the late 1960 s and early 1970s was conducive to newly recognised forms of sexual politics which challenged the heteronormative and 
rather phallocratic mindset of the times while opening up new vistas for apprehending the diverse range of invisibilised sexual behaviours. A series of landmark actions would coalesce into a climate of political activism which would inspire the Balmain group of writers to be more liberal in their writings: gathering momentum in the 1970s, the Daughters of Bilitis, a Melbourne-based lesbian organisation, was founded in 1969 when the first signs of the Australian women's liberation movement were patent (Moorhouse 1972, 173-76); the Campaign Against Moral Persecution (abridged as C.A.M.P.) was created in June 1970; Germaine Greer's The Female Eunuch and Dennis Altman's Homosexual: Oppression and Liberation were respectively released in 1970 and 1971; the Melbourne University Gay Liberation Front was founded in 1972. These are just a few examples. That same year, book censorship came to an end, thus coinciding with the election of Gough Whitlam's Labor Government. In terms of birth control, the pill and abortion ${ }^{4}$ were made more widely accessible at a time of unrestrained sexual freedom as the AIDS epidemic was only to strike in the next decade. Narratives such as Frank Moorhouse's The Americans, Baby: A Discontinuous Narrative of Stories and Fragments $(1972)^{5}$ and Michael Wilding's Living Together (1974), written in this particular era of sweeping changes, are bound to be impregnated with these consciousness-raising discourses which are occasionally treated on a comical or sour note. For instance, after challenging Martin's manhood so that he would have sex with her, Mrs. Bilham sarcastically states: “They talk about women's liberation but what they need for Godsake is men's liberation" (Wilding 1974, 140). By contrast, the cute romance between Hugo and Cindy in "The Story of Nature" morphs into a bitter fight informed by feminism and gender politics (Moorhouse 1972, 48-9).

It turned out that the counterculture revolution of the 1960s-70s, encouraged by unashamed hedonism, was an anti-establishment movement which liberated sexual expression equally in homes and in print.

\section{The Poetics of Sexuality: The Erotics of Writing Sex in Text}

Through the scenography and curation of literary representations, the novel as a genre has a capacity for offering a mediation of reality which, ultimately, can be merely dismissed as "entirely fictitious." This very quality could be deemed particularly convenient when the reality in question - like having open relationships - is likely to displease or offend conservative readers. When not presented as pure artistic fabrication, literary representations of sexuality have traditionally been euphemistically or suggestively portrayed, lest the salacious texts be branded as indecent or pornographic and be subject to censorship. Michael Wilding's countercultural art of dealing with "dirt" (a word understood here as licentious subject-matter) in Living Together is essentially and primarily to make good use of "the delicacies and sensitivities of language" by mentioning sex obliquo ductu through a series of linguistic and narrative strategies. ${ }^{6}$ Wilding makes extensive use of the many roundabout ways that language offers to indirectly address delicate matters like sex: diegetic speculations through the use of rhetorical questions $(1974,8)$, qualifying words ("probably," "seemed to," 11,31), conditional clauses ("as if," 76), similes ("like a couple of sex-starved crows," 34$)$, obscene profanities $(12,14)$, to mention a few. 
11 In terms of narrative strategies, the novelist shifts the focus of libidinal energy on the eroticism of art (Wilding 1974, 116) and on various discussions of intimacy to mention sex-related matters, i.e. anatomy and sex. These discussions are either led by the omniscient narrator or by the characters $(83,92-3,101,147,168-9,188-9)$. This avoidance of depicting in-your-face sexual scenes, scenes which readers will find more readily in Moorhouse's stories, is also achieved through the use of reported saucy action in dialogue (74-5) and diegetic counterfactual scenarios imagined either by the characters (91) or by the omniscient narrator (165-6). Functioning to some extent as the author's mouthpiece in this very passage, the narrator declares:

The delicacies of the human couple were not something to be illustrated by diagram and slide and dissection; the glancing, shifting, evanescent, always readjusting, protean nature of those human contacts could be alluded to only by the delicacies and sensitivities of language [...]. $(1974,42)$

12 As the exception which proves the existence of the rule, there is just one non oblique graphic depiction of sex in Living Together. It involves the arousal and exploits of the sex-obsessed and flighty Martin fornicating with his liberated neighbour Mrs. Bilham. She acts as a counterpart figure to the equally liberated Gretel Mann, who seduced Paul earlier on in the narrative. Like most male literary perspectives on mainstream heterosexuality, this scene of exhibitionist sex emphasises penile performance ("He watched her, his erection grown huge [...]," Wilding 1974, 140) but it also ends up in a comical fiasco defeating the masculine sexual prowess and orgastic satisfaction one half-expects from male fantasy scenarios, when interrupted by Mrs. Bilham's kitchen catching on fire. The involuntary coitus interruptus leaves Martin with an overwhelming feeling of frustration:

It was not the full horror of it that initially pressed on him in the morning but the uncertainty of whether he could claim to have slept with Mrs. Bilham or not; claim even to himself; the very term slept with indicated some of the problem, applying it to that unrestful activity; but that was only part of the problem; for whatever name used, there was still the uncertainty about the action whose incompleteness could hardly merit full recognition. It depended of course on whether screwing someone meant just penetration or orgasm; screwing suggested simple movement, with no necessary final culmination. (147)

Whether Michael Wilding is trying to downplay the importance of sex with lightweight humour or is too coy to insert a serious warts-and-all pornographic depiction in Living Together is ultimately for readers to decide.

13 Back in the 1970s, the Balmain Group of Writers were creating a sexually provocative set of texts that would demarginalise and legitimise forms of sexualities which were given more visibility in Australian culture following the sexual revolution. Whether they write respectively indirectly and directly about sex, Michael Wilding and Frank Moorhouse show, terminology-wise, no restraint in discussing sex. They do not hesitate to call a spade a spade or - to be more to the point - a prick a prick. However, we might argue that Moorhouse is a bit more daring and democratic in his exploration of a wider gamut of sexual practices in The Americans, Baby: straight anal sex, group sex, same-sex intercourse, hand job, casual sex, extra-marital affairs, intergenerational sex, autoeroticism, (mutual) oral sex, and sexual fantasies. Moorhouse's insightful observations of interpersonal rapport and seduction take the sexual element to be the cornerstone of human nature and desire. His "discontinuous narrative" technique, which gives episodic insights into the lives of his characters, makes heterosexual or homosexual sexual intercourse appear like a long conversation which could be 
interrupted, resumed, or terminated at any time. In Moorhouse's politically-inflected "stories and fragments," sexual encounters are seldom allusively portrayed. On the contrary, they feature in more straightforward accounts, no matter how scandalous the 1970s readership might have deemed them to be.

However, the author would occasionally use the oblique way to include more hardcore material like deviant practices. There is no first-degree representation of characters practising zoophilia but there is a second-degree depiction of it. It is subtly reported as being taken from a fictitious paper, namely one pertaining to the counterfactual world Moorhouse imagined in "Soft Drink and the Distribution of Soft Drink": "Becker had once, and only once, read an obscene New York newspaper called the National Expose. There was something from that paper which described a girl and a dog" $(1972,169)$. Similarly, in the climaxing story titled "The Letters to Twiggy," a thirty-six-year-old Senior Lecturer in History has pedophilic sexual fantasies about raping teenage British model Twiggy, disturbing fantasies which he expresses in an anonymous letter (21819). These two pages of crude depictions in The Americans, Baby consequently turn the whole book into pedopornographic material: “I'm coming across to England and will drag you off to a motel and rip your beautiful Protor and Babbs Carnaby Street clothes off and your little silk panties, tie your hands and legs to the bed and ram my prick up your little girl's twat until you scream with pain" (218). The graphic fantasies even take a bisexual turn in which Twiggy, abusively addressed in this letter as "Twatty," is imagined to be a sex-starved gay twink. Twiggy, Twatty, twink: Moorhouse slips from one idea to the next through lexical kinships and phonetic associations (the /tw/ alliteration in this instance). Twiggy's name being evocative of "twat" gives rise to a sex-inflected story while the further phonetic association with "twink" gives it a bisexual twist.

Admittedly, Freud's intuitions have largely contributed to turning the harmony between creativity and sexuality into a truism. On the one hand, in Three Essays on the Theory of Sexuality (1905), it is Freud's theory of the libido which makes sexual energy the bedrock of all human activity; while on the other hand he advances the concept of sublimation, a process that realises the mutation of the sexual drive (Trieb) into professions, especially artistic ones, "apparently unrelated to sex, but finding their aptitude in the force of sexual instinct" (Laplanche and Pontalis 1967, 465). Stylistically speaking, the inclusion of sex and the courageous depictions of alternative lifestyles and sexualities in the corpus under scrutiny (namely essentially group sex in Living Together and gang banging, gay sex or random sex in The Americans, Baby) are as much a manifestation of the author's sublimated sexual drive (which morphed into literary representations of sexual desire) as they are the essence of the characters' sexual energy in Wilding's and Moorhouse's fictitious worlds. Therefore, intriguingly, these sexualised stories have become the vehicle for venting the sexual drive of which literature is meant to be the sublimation.

Beyond its obvious aesthetic appeal as a novel literary concern, the pending question resulting from the sexualisation of fictitious narratives is to determine whether or not sex in text is but a mere commercial trick to boost book sales. 


\section{The Politics of Sexuality: The Counter-Cultural Art of Dealing with Dirt}

17 It might be fair to point out that a cluster of combined factors contributed to the relaxation of censorship and to the increased use of sex in text. First and foremost, there was an established tradition of "anti-wowser" cultural production going back to Norman Lindsay which gained momentum in the 1960s with Barry Humphries' Australian tour in 1962 and the emergence of highly controversial $O z$ magazine in 1963, under the editorship of Richard Neville, Richard Walsh, and Peter Grose. Parallel to this movement, writers were becoming increasingly professionalised through the Federation of Australian Writers while the Australian Society of Authors, in which Moorhouse played a key role, was agitating against censorship.

In the following decade, the loosening of the censorship laws and sexual mores enabled the countercultural Balmain Group to indulge in libertine literary representations which opened up new perspectives in Australian literature. Such freedom of sexual expressiveness certainly broadened the Australian erotic fiction repertoire or at least, it paved the way for more daring representations of bodily activity in Australian fiction, especially when the mention of sex was more tentative (i.e. simply discussed among characters or by the narrator rather than having their physical exploits depicted more directly). For Wilding and Moorhouse, discussing sex transgressively might have had the same liberating and empowering effect ${ }^{7}$ as the actual experience of having sex.

In essence, the subversive counter-culture questioned and directly challenged mainstream heteronormativity by highlighting a generation gap between an older generation clinging to traditional pre-feminist ideas of sexualities attached to family values and a more liberated group of people - some of whom are referred to as hippies - who discussed sexual orientation more freely and who were keen to explore the joyous repertoire of sex, as portrayed in Living Together. As Ian Harold Jamieson explains,

Freedom from parents and social restraints was an important reason for living together, but at the core of it all was the freedom to have sex. Sex was integral to the transgressive and disruptive efficacy of living together. Without the sex you have an accommodation arrangement that may have aroused the suspicion of mainstream society, but not its ire, as without the sex living together presented much less of a real threat. Living Together deals with young people who have chosen to ignore the institution of marriage and who have decided to live together in a sexual relationship. $(2009,156)$

This relaxing of mores in the 1970s enabled authors such as Frank Moorhouse to write erotic stories for commercial gain and to somewhat assert their marginalised sexual orientations. It is most fitting that Moorhouse, whose stories were the target of censorship as early as the 1950s and who was a spearheading figure in the anticensorship campaigns of the 1970s, should come to symbolise this sexual revolution in print. Damien Barlow contends that "Moorhouse's short story collection, The Americans, Baby (1972), provides a lasting literary example of this heady resurgence in left-wing thought, especially the desire to bring sex and politics out of the closet to challenge the norms of Australian society with a dissenting "porno-politics"' $(2013,309)$. Michael Wilding and Frank Moorhouse were essentially trying to give an accurate literary representation of the sexualisation of Australian society following the influence of the 
American sexual revolution in the 1960s. Taking his generation on a trip down memory lane, Wilding recalls that

[a]t that time Australia was politically very conservative but the actual lifestyle of the city was very liberated. There was a discrepancy between the way people were living and what was being written in the literary record. The group I knew, what we were trying to do was write about the living experience we knew, to find a way to get that into literary form, to deal with this new material. And in a sense that was the literary revolution of the early 1970s. (qtd. in Syson 2019)

These two authors were blurring the lines of clear-cut sexual distinctions and practices. Frank Moorhouse, in particular, was diligent in depicting relationships and sociological communities that were not sufficiently widespread to be integrated into the norm: homosexuals, whether closeted like Carl or openly gay like Paul (see "The American Paul Jonson," "Who is Sylvia," "Jonson's Letter"), bisexuals (see "The Letters to Twiggy") and cross-dressers (see "Becker and the Boys from the Band"). Beyond the sexual freedom of unattached individuals who were encouraged to be sexually adventurous by engaging with a bountiful array of sexual practices (barring the illegal deviant ones such as pedophilia or zoophilia - both of which are alluded to in The Americans, Baby), there was the breaking of an even greater taboo: open relationships. These affairs directly challenged monogamous couples whose sexuality was held within the confines of auto-erotism and one-to-one fornicative sessions.

In Michael Wilding's and Frank Moorhouse's stories, which display the occasional inclusion of some crude anatomical descriptions, sexual intercourse is depicted as part and parcel of a naturalistic tableau. These sexualised narratives, which can neither be labelled erotic nor pornographic, offer a greater sense of verisimilitude, the bedrock of realism which has been prevalent in Australian novels from the first one published in 1831 all the way to the early 1970s. Living Together and The Americans, Baby stretch the boundaries of the Australian novel genre by including the intimacy in the private sphere which up until the 1970s was prudishly censored. Readers going through Michael Wilding's autobiography Growing Wild (2016) will discover that two of his stories, "The Phallic Forest" and "The Image of a Sort of Death," were expunged by the University of Queensland Press vice-chancellor Zelman Cowen from Wilding's first collection entitled Aspects of the Dying Process (1972), specifically because of their explicit sexual content. ${ }^{8}$ They later reappeared in The Phallic Forest (1978) published six years later by Wild and Woolley. When coming across sexual references, readers might feel a stronger connection with Wilding's and Moorhouse's characters once they realise that their immersive experience of these authors' counterfactual worlds is no different from their daily experiences of life.

Writing about sex in Australian fiction could be utilized as a seductive lever to make a wider audience take a vested interest in Australian fiction. In terms of reading strategies, sex helps optimise the attention of readers as interest and importance are two key factors correlated to attention. The inclusion of power words as in sexual vocabulary (in Living Together: "suck," "fucks," "raping,"“defloration," "prick," “penis," "genitals" and "genitalia" / The Americans, Baby: "penis," "vagina," "half an erection," "she was aroused," "I entered her," "I had my first orgasm," "cock," "fucking," etc.) or any other words and phrases conjuring sexual imagery (Living Together: "obscenity," "that gets you all excited," "naked," "nipples," "intimacies" / The Americans, Baby: "lovemaking," "Do you want to go to bed with me?," "that physical expression of this love," "The ecstasy of nude bodies") is instrumental in attracting and harnessing the reader's 
attention. These words, which are to be found in Wildings's and Moorhouse's fiction, have a strong emotional anchor which triggers arousal (a term also used in research as a byword for interest) in readers. Molecular biologist John Medina notes that "the brain continuously scans the sensory horizon, with events constantly assessed for their potential interest or importance" $(2008,76)$. He further explores the reciprocity of this principle, whereby interest could potentially be created through channelled attention and shows how marketing strategies have aptly used this technique. This is all the truer as emotionally arousing elements are more likely to stick in people's memory than ordinary or neutral ones: "When the brain detects an emotionally charged event, the amygdala releases dopamine into the system. [...] [D]opamine greatly aids memory and information processing [...]" (80-1). The limbic system is responsible for controlling emotional drives and the satisfaction of our basic needs such as sleep (hypothalamus), sexual drives (amygdala) and appetite (hypothalamus). In La séduction de la fiction, I hypothesise that appetite for sex (libido) and sex to create appetite in text (the erotics of reading fiction) would be encouraged by a contiguity principle which would be triggered by the proximity of these brain regions. Similarly, issues of functional connectivity in the phantom limb syndrome would be explained by the brain's capacity to create new neural connections. ${ }^{9}$ Given time, neuroscientific research will have the last word on this speculative thesis.

The works under consideration are either early (Moorhouse) or debut (Wilding) narratives published in the early 1970s, by emerging writers who are the products of the heavily politicised 1960s which fuelled them with idealism and a sense of activism. They developed their distinct voices while experiencing the responsibility-free alternative lifestyle proposed by the hippie culture of the early 1970s. In the process, they also tried to maximise public attention with licentious content by turning literary texts into erogenous zones. If they were to be labelled libertines, it would be in the sense of them being not so much dissolute writers as freethinkers, emancipated writers who broke free of the conventional rules of literary narratives. Obviously, the Balmain writers' sex-laden stories paved the way for upcoming generations of writers like Justine Ettler, Linda Jaivin, John Purcell (intriguingly writing under the female pen name of Natasha Walker), Petra Spear and Christos Tsiolkas, who would unashamedly exhibit carnal love in their narratives, be they part of mainstream genres such as grunge fiction or of more specialised areas of literature such as erotic fiction and pornography. It thus becomes apparent that the 1970s encapsulate the pivotal decade for Australian representations of sexualities in Australian novels.

\section{BIBLIOGRAPHY}

ANDERSON, Don. 1995. Text \& Sex. Sydney: Vintage.

BARLOW, Damien. 2013. “Porno Politics Frank Moorhouse's The Americans, Baby.” In Telling Stories: Australian Life and Literature 1935-2012, edited by Tania Dalziell and Paul Genoni, 308-14. Clayton: Monash University Publishing. 
COLE, Creagh McLean. 2018. “John Anderson.” In The Stanford Encyclopedia of Philosophy, edited by Edward N. Zalta. https://plato.stanford.edu/archives/spr2018/entries/anderson-john/.

DESSAIX, Robert. 1993. Australian Gay and Lesbian Writing: An Anthology. Melbourne: Oxford University Press.

FARRELLY, Elizabeth. 2009. "When the Push Came to Shove." Sydney Morning Herald, 4 April. https:// www.smh.com.au/national/when-the-push-came-to-shove-20141112-9qi9.html.

JAMIESON, Ian Harold. 2009. "Sex and the Sydney Context of Michael Wilding's Early Fiction." PhD diss., University of Western Sydney. https://researchdirect.westernsydney.edu.au/islandora/ object/uws\%3A8915.

KAMPMARK, Nataša. 2014. “Australian Literature in Serbian Translation.” JASAL: Journal of the Association for the Study of Australian Literature 14, no. 1 (2014): 1-14.

MEDINA, John. 2008. Brain Rules: 12 Principles for Surviving and Thriving at Work, Home, and School. Melbourne: Scribe.

MOORHOUSE, Frank. 1972. The Americans, Baby: A Discontinuous Narrative of Stories and Fragments. Sydney: Angus and Robertson.

PONS, Xavier. 2001. "Erotic Writing in Australia - Then and Now." In Changing Geographies: Essays on Australia, edited by Susan Ballyn, Geoff Belligoi, Kathy Firth, Elisa Morera de la Vall and Bill Phillips, 269-77. Barcelone: Centre d'Estudis Australians, Universitat de Barcelona.

PONS, Xavier. 2009. Messengers of Eros: Representations of Sex in Australian Writing. Newcastle Upon Tyne: Cambridge Scholars Publishing.

RAMACHANDRAN, V.S. 2011. The Tell-Tale Brain: A Neuroscientist's Quest for What Makes Us Human. New York: W.W. Norton.

VERNAY, Jean-François. 2019. La séduction de la fiction. Paris: Hermann.

WARD, Anna E. "Sex and the Me Decade: Sex and Dating Advice Literature of the 1970s." Women's Studies Quarterly 43, no. 3-4 (Winter 2015): 120-36.

WILDING, Michael. 1974. Living Together. St Lucia: University of Queensland Press.

WILDING, Michael. 1998. “After Libertarianism: An Interview with Michael Wilding," interview by Ian Syson, Australian Literary Studies 18, no. 3: 280-97.

WILDING, Michael. 2016. Growing Wild. Melbourne: Arcadia.

\section{NOTES}

1. Text \& Sex (Sydney: Vintage, 1995), in which Don Anderson repackaged a selection of his popular media articles, investigated sex politics and stylistics prior to 2009 without narrowing down the focus to Australian writing.

2. Private correspondence with Michael Wilding, 25 June 2019.

3. Private correspondence with Christine Townend, 5 June 2019.

4. Up until September 2019, in New South Wales, it was still considered a crime to have an abortion if there was no foreseeable danger induced by the pregnancy or by giving birth. In comparison with other countries, Australia was not at the vanguard, to say the least. For instance, whatever the reasons for choosing it, abortion was decriminalised in France as early as 1975. 
5. It is difficult to consider Frank Moorhouse's narratives before 1993 as novels since the author repudiates the genre. Some of his collections of prose - Futility and Other Animals (1969), The Americans, Baby (1972), The Electrical Experience (1974) - were subtitled "discontinuous narratives," a concept taken from The Salzburg Tales (1934) by Christina Stead that linked the stories of various independent characters.

6. To account for the stylistic allusiveness of Australian erotic writings by Rod Jones, Justine Ettler and Linda Jaivin published in the mid 1990s, Xavier Pons posits that the dominant Christian culture which represses sex for its association "with the animal side of human nature" is responsible for oblique representations of sex in literature through the stylistic use of figures of speech (Pons 2001, 270). This explanation could hardly apply to the racy stories by the Balmain group of writers because a majority of them, even though they might have had a religious education through schooling, were agnostic.

7. As Xavier Pons has it, "If pleasurable sex is sex that produces a feeling of empowerment, it means it has a lot to do with transgression - the breaking of rules or norms which gives the transgressor a sense of being above the law or of being more daring than the common run, thus producing a sense of power which translates into pleasure - what John A. Scott calls 'the exhilaration of sin.' A sense of well-being and freedom results from transgression, much as Roland Barthes contended that 'perversion makes one happy; or, to be more accurate, it produces $a$ plus"' (2009, 5).

8. Ian Harold Jamieson observes that "in Aspects of the Dying Process sex is an important issue, but in Living Together it has moved to a position of centrality; it is integral to the concerns of the novel and accordingly the treatment is more comprehensive and explicit" $(2009,155)$.

9. See V.S. Ramachandran, The Tell-Tale Brain: A Neuroscientist's Quest for What Makes Us Human (New York, W.W. Norton, 2011), 28: "Now, how to explain the bizarre tendency to attribute touch sensations arising from the face to the phantom hand? The orphaned brain map continues to represent the missing arm and hand in absentia, but it is not receiving any actual touch inputs. It is listening to a dead channel, so to speak, and is hungry for sensory signals. There are two possible explanations for what happens next. The first is that the sensory input flowing from the facial skin to the face map in the brain begins to actively invade the vacated territory corresponding to the missing hand. The nerve fibres from the facial skin that normally project to the face cortex sprout thousands of neural tendrils that creep over into the arm map and establish strong, new synapses. As a result of this cross-wiring, touch signals applied to the face not only activate the face map, as they normally do, but also activate the hand map in the cortex, which shouts 'hand!' to higher brain areas. The net result is that the patient feels that his phantom hand is being touched every time his face is touched."

\section{ABSTRACTS}

In the 1970s, the loosening of the censorship laws and sexual mores enabled the countercultural Balmain Group to indulge in libertine literary representations which opened up new perspectives in Australian literature. Among them, let us mention freedom of sexual expressiveness, the broadening of the Australian erotic fiction repertoire, the addition of a new dimension to realism, daring depictions of alternative lifestyles and sexualities, the challenging of mainstream heteronormativity, the expression of a subversive counter-culture, the expansion of the boundaries of the Australian novel genre. These new approaches to sexuality, as evidenced by 
explicit sex scenes probing a wide range of sexual practices, have shaped a sexual revolution in print and a counter-cultural art of dealing with dirt (understood as licentious subject-matter) which my paper will try to conceptualise. I shall restrict my scope to material published in the 1970s by analysing the prose written by some of the Balmain Group authors such as Frank Moorhouse and Michael Wilding.

\section{INDEX}

Keywords: Balmain group, sexuality, the Sydney Push, counter-culture, Frank Moorhouse, Michael Wilding

\section{AUTHOR}

\section{JEAN-FRANÇOIS VERNAY}

CIEE (Council on International Educational Exchange), Global Institute, Sydney Jean-François Vernay has published four monographs: Water from the Moon: Illusion and Reality in the Works of Australian Novelist Christopher Koch (Cambria Press, 2007), A Brief Take on the Australian Novel (Wakefield Press, 2016), The Seduction of Fiction: A Plea for Putting Emotions Back into Literary Interpretation (Palgrave Macmillan, 2016) and La séduction de la fiction (Hermann, 2019). His latest books are an edited volume entitled The Rise of the Australian Neurohumanities: Conversations Between Neurocognitive Research and Australian Literature, and a monograph under the title of Neurocognitive Interpretations of Australian Literature: Criticism in the Age of Neuroawareness, both released by Routledge in 2021. Vernay's books have been, or are in the process of being translated into English, Arabic, Mandarin, and Korean. 